\title{
Crossed Fused Left Renal Ectopia- A Rare Anomaly
}

\author{
Vasudha Nikam ${ }^{1}$, Arun Karmalkar ${ }^{2}$, Shailesh Srivastava ${ }^{3}$
}

\begin{abstract}
Crossed renal ectopia occurs when the kidney is located on the opposite side. It is the second most common fusion anomalies after horseshoe kidney. Ectopic kidney occurs as a result of a halt in migration to their normal location, during embryonic period. Here we present a case of fused right renal ectopia which was found during routine dissection in 59 years old male cadaver; where the right kidney was horizontal and fused to lower pole of left kidney. Proper knowledge of morphological variations of kidney along with its vasculature is necessary for anatomist as well as for urologist who will help to diagnose the renal anomalies and transplantation surgery.
\end{abstract}

Keywords: Crossed fused renal ectopia, Fusion anomalies of kidney, Malrotation and migration of ureteric bud, Aberrant renal vessels, Left L shaped kidney

\section{Introduction}

When a kidney is located on the side opposite from which its ureter inserts into the bladder; it is defined as crossed renal ectopia and if it is fused with the opposite kidney then it is defined as fused renal ectopia (1).

Fusion anomalies of the kidneys are divided into two distinct varieties, horseshoe kidney and crossed fused renal ectopia $(2,3)$. Horseshoe kidney accounts for $90 \%$ of all renal fusion anomalies (4) and occurs in $0.25 \%$ of the population (5). Crossed fused renal ectopia is the second most common fusion anomalies of the kidney (4) and has an incidence of approximately $1: 1000-1: 7500(3,6,7,8,9)$. The male predilection for such anomaly is $2: 1$; in addition to that, left to right ectopy is three times more common and is about $67 \%(8,9)$

Most of the cases of crossed renal ectopia are diagnosed at autopsy or incidentally during radiological investigation or during cadaveric dissection $(10,11)$. The aberrant renal vascular supply arises from either right or left side of aorta or from the common or external iliac arteries (12). Though mostly undiagnosed throughout life crossed fused ectopic kidneys with aberrant vasculature could provide a formidable challenge during aortic reconstructive surgery for post renal-aortic and aorto-femoral aneurysms (11).

Here we report a case of a crossed fused renal ectopic kidney found in the left lumbar region of male cadaver during the dissection. The present case reports not only the anomaly but also explains the embryological basis of this rare congenital anomaly.

\section{Case Report}

During the routine cadaveric dissection of abdomen in the dissection hall of Department of Anatomy at D.Y.Patil Medical College, Kolhapur; we came across a mass in front of vertebral column at the level of L4 vertebra below the origin of inferior mesenteric artery extending in front of abdominal aorta and inferior vena cava and extending on left side of vertebral column. We carefully dissected the specimen which revealed the presence of an ectopic right kidney fused to the lower pole of left kidney with aberrant renal vessels at its right end. (Fig no-1). The dimensions of fused renal mass were horizontally $14.6 \mathrm{cms}$ and vertically $17.2 \mathrm{cms}$

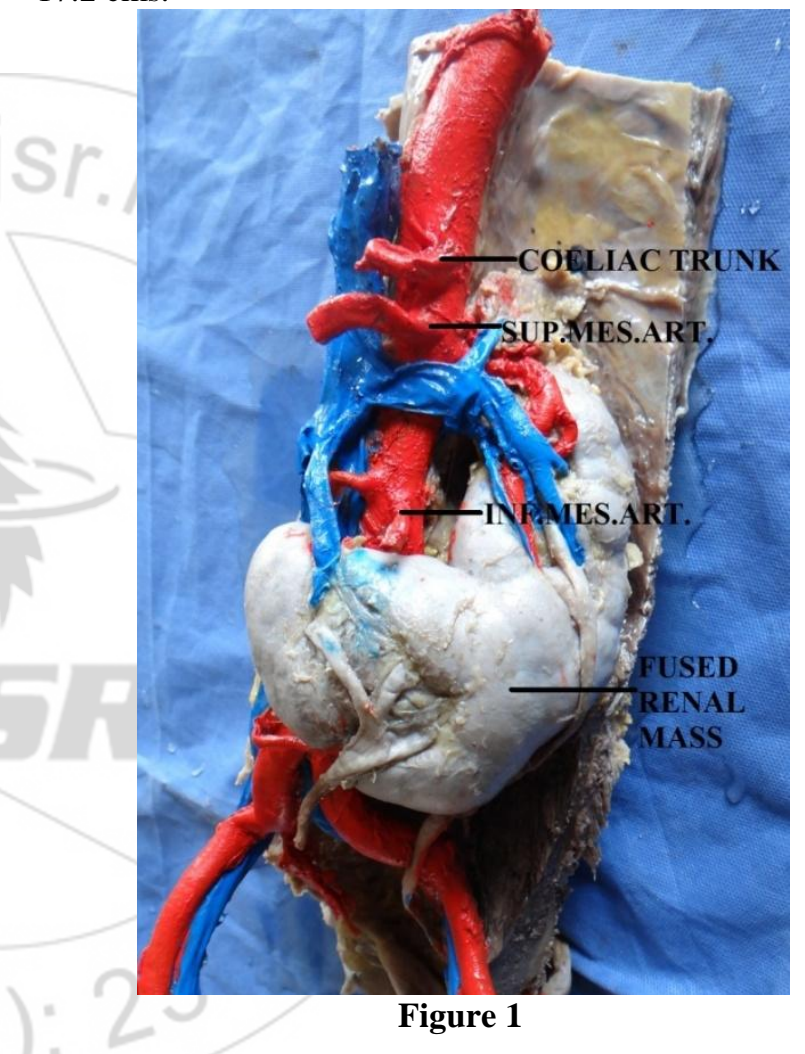

\section{Gross Features of Fused Renal Mass}

The fused ectopic renal mass showed lobulated appearance and was situated infront of left psoas major vertically and infront of major blood vessels of abdomen horizontally and was situated above the pelvic brim. The mass extended vertically on the left side from L1 vertebra to L4 vertebra, starting from left lumbar to left iliac region then extending horizontally along L4 vertebra overlapping the bifurcation of abdominal aorta.

Careful dissection revealed that the right kidney has crossed the midline and runs horizontally to fuse to the lower end of left kidney, left kidney was vertical in position showing the normal position indicating the proper ascent. But the right kidney has failed to ascent properly and is placed horizontally and fused with the lower end of left kidney. 


\section{International Journal of Science and Research (IJSR) \\ ISSN (Online): 2319-7064 \\ Index Copernicus Value (2013): 6.14 | Impact Factor (2015): 6.391}

Two separate hila were seen which were facing anteriorly, one was situated $1.05 \mathrm{cms}$ from the abdominal aorta while the other was situated at the right and lower end of fused renal mass. On the right side in the hilum there were three major calyces seen prominently which fused to form the right renal pelvis while on the left side in the hilum two major calyces were seen which fused to form the left renal pelvis (Fig no-2). Both the ureters were normal; the right ureter crossed the left common iliac vessels while the left ureter crossed the left external iliac vessels. The two ureters entered the bladder normally but the right ureter crosses the midline (Fig no-3).

\section{Vasculature of Fused Renal Mass}

Renal arteries- There were two renal arteries which arise from aorta at the level of L2 vertebra; both the arteries entered the respective hilum. In addition to these main arteries there was an accessory renal artery supplying the right end of the mass and was arising from right common iliac artery and entered the hilum below the pelvis of right ureter (Fig no-4).

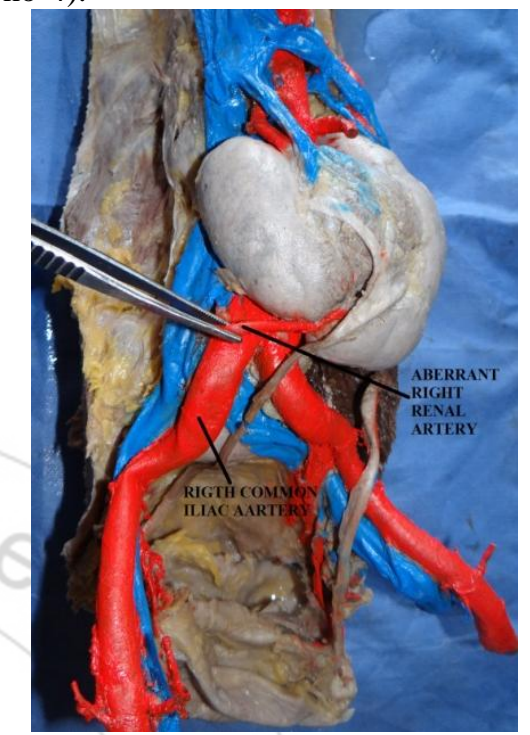

Figure 4

Renal veins- Four small renal veins were arising from the hilum of left kidney which fuses to form the left renal vein showing normal course receiving left suprarenal vein and left testicular vein normally. On the right side two renal veins one at the upper end of the hilum and second at the lower end of the hilum drain separately into inferior vena cava, these vessels crossed the midline to drain into inferior vena cava. One more small renal vein arise from the posterior aspect of renal mass which courses behind the aorta and drains into left renal vein (Fig no-5). Both the suprarenal glands were present in the normal position and also no change in the yascularity of suprarenal glands was noticed.

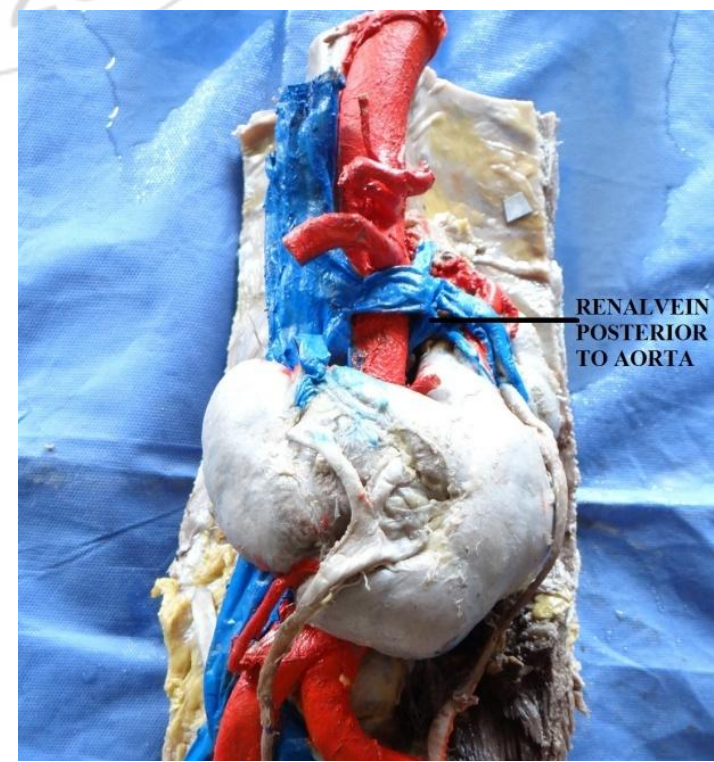

Figure 5

Volume 5 Issue 5, May 2016 www.ijsr.net 


\section{International Journal of Science and Research (IJSR) \\ ISSN (Online): 2319-7064}

Index Copernicus Value (2013): 6.14 | Impact Factor (2015): 6.391

\section{Embryological Basis}

Development of kidney starts at the 4th week of gestation by the interaction between the ureteric bud and the nephrogenic cord at the level of S2 vertebra in the pelvis (10). The ureteric bud enters the metanephric blastema to induce the changes in the developing kidney from $4^{\text {th }}$ week to $8^{\text {th }}$ week of intrauterine life (13). Further during $6^{\text {th }}$ to $8^{\text {th }}$ week of development the foetal kidney ascends along the posterior abdominal wall from pelvis to its normal position in lumbar close to the developing suprarenal gland. Initially the hilum faces anteriorly with both the kidneys being placed closed to each other. During its ascent it undergoes $90^{\circ}$ axial rotation from horizontal to medial resulting in rotation of hilum from anterior to medial side (10). The upward migration of ascending kidney could be arrested by several causes such as enlarged umbilical arteries on the right or undue persistence of caecum in right lumbar region before reaching its final position in the right iliac fossa (last $180^{\circ}$ rotation of midgut around the axis of superior mesenteric artery). This results in migration of right ascending kidney to the left to create two kidneys on the left side of the spine hence the crossed fused renal ectopia (13). It is postulated that if compression factor of the umbilical arteries persist at the beginning of the cranial migration in the presence of two unequal metanephric masses, the result will be crossed ectopia (2, 19).

Also the ureteric bud is solely responsible for this fusion anomaly, migration of right ureteric bud to the left induces the left metanephric blastema twice to form both kidneys on the left side of the abdomen ( the right kidney being ectopic and rudimentary fuses to the lower end of left kidney, while the left kidney is normal (14).

\section{Discussion}

Renal fusion and anomalies were first studied and classified by Wilmer in 1938 later it was revised by McDonald and McClellan in 1957. They classified the ectopic sequel into four major types as -

1) Crossed ectopia with fusion- $90 \%$

2) Crossed ectopia without fusion- uncommon

3) Solitary crossed ectopia -very rare

4) Bilaterally crossed ectopia- extremely rare $(1,2,8,10)$.

Six variations of crossed fusion have been described these are; type 1-inferior crossed fused ectopia, type 2- sigmoid or S shaped kidney, type 3- unilateral lump kidney, type 4unilateral disc kidney, type 5- L shaped kidney and type 6superior crossed fused ectopia $(1,2)$. In present study the anomaly is ' $L$ ' shaped and crossed kidney lies inferiorly and transversely. The factors responsible for such type of ectopia and fusion were still undetermined. However the crossover occurs as a result of pressure exerted by abnormally positioned umbilical arteries that prevent the normal ascent of kidney which follows a path of least resistance to the opposite side $(8,11)$.

Apart from this type of fusion anomaly, another one is horseshoe kidney which is most common fusion anomaly. The horseshoe kidney can be differentiated from crossed fused ectopia in which both fused kidneys lie on one side of spine $(13,16)$. In present study the right kidney lies horizontally crossing the midline and fuses with the lower pole of left kidney and lies below inferior mesenteric artery.

In most cases the fusion is between the lower pole of the orthotropic kidney and the upper pole of the ectopic kidney. It is usually the left kidney which crosses to right $(1,14,17$, 18). But in present study the right kidney has crossed and fused with the lower pole of left kidney which makes it a rare anomaly. The present study indicates the caudal part of mesonephric ducts were normal which created normal trigone inside the bladder, while the cranial part of ureteric bud is migrated towards left metanephric blastema and fuses with the lower pole of left kidney. The lobulated appearance of fused renal mass together with aberrant renal vessels arising at variable levels from abdominal aorta, suggest the presence of many anomalous segmental arteries of embryonic origin supplying the metanephric blastema and ureteric bud (11). In present study one aberrant artery is present on the right side of fused renal mass and supplies the right end of the renal mass and enters through the right hilum. This aberrant artery in our study arises from right common iliac artery which may be non-degenerated part of embryonic accessory renal artery.

Most of the patients with crossed fused renal ectopia are usually asymptomatic during life and are diagnosed incidentally $(9,14,20)$; they do present with increased susceptibility to develop complications such as urinary infections, urolithiasis and abdominal masses.

\section{Conclusion}

Most of the patients with crossed fused renal ectopia are asymptomatic and are diagnosed incidentally. These patients are prone for chronic and recurrent urinary tract infections, urolithiasis, hydronephrosis and hypertension which are due to anomalous vascular pattern. In present study the ectopic right kidney fuse to the lower pole of left kidney with aberrant renal vessels. This highlights the uncertain anatomy and embryology of such rare congenital anomaly.

The objective of the case report is to highlight the importance of prenatal diagnosis by Ultrasonography, CT Urogram and postnatal follow up in the evaluation and management of renal anomalies. Early diagnosis of such anomaly is important for long term follow up.

\section{Acknowledgement}

Thanks to President, Chancellor, Vice Chancellor, Dean of the Medical College, and my colleagues, D.Y.Medical College, Dr.D.Y.Patil University, Kolhapur.

\section{References}

[1] Shailesh Solanki, Veereshwar Bhatnager, Arun K Gupta, Rakesh Kumar; Crossed fused renal ectopia: Challenges in diagnosis and management: Journal of Indian Association of Pediatric Surgeons; Jan-Mar 2013/ Vol 18/ Issue 1/pp-7-10. 


\section{International Journal of Science and Research (IJSR) \\ ISSN (Online): 2319-7064 \\ Index Copernicus Value (2013): 6.14 | Impact Factor (2015): 6.391}

[2] Gheorghe Pupca, Gratian Dragoslav, Viorel Bucuras, Nicoleta Iacob, Ioan Sas, Petru matusz, Marios Loukas; Left crossed fused renal ectopia L-shaped kidney type. With double nutcracker syndrome (anterior and posterior);Rom J Morphol Embryol 2014, 55 (3 Suppl): 1237-1241.

[3] Glodny B, Petersen J, Hofmann KJ, Schenk C, Herwig R, Trieb T, Koppelstaetter C, Steingruber I, Rehder P; Kidney fusion anomalies revisited: clinical and radiological analysis of 209 cases of crossed renal fused ectopia and horse shoe kidney. BJU Int, 2009, 103 (2): 224-235.

[4] Turkvatan a, Olcer T, Cumhur T; Multidetector CT Urography of renal fusion anomalies, Diag Interv Radiol, 2009, 15 (2) 127-134.

[5] Bauer SB: Anomalies of upper urinary tract, In:Wein AJ, Kavoussi LR, Novick AC, Partin AW, Peters CA (eds) Campbell-Walsh urology, $9^{\text {th }}$ edition, Saunderselsevier, Philadelphia, 2007, 3269-3304.

[6] Hochwald O, Shaoul R; Crossed fused ectopic left kidney, Arch Dis Child, 2004, 89 (8), 704.

[7] Rinat C, Farkas A, Frishberg Y; Familial inheritance of crossed renal ectopia, Pediatr Nephrol, 2001, 16(3), 149-154.

[8] Rajaram V, Govindarajan M; Crossed Fused Renal Ectopia- a Case Report; International Journal of anatomical sciences, 2011, 2(2),19-21.

[9] Dr. Imran Nazir salroo, Dr. Arsheed Iqbal, Afroza Jan; Crossed Fused Ectopic Right Kidney with Fusion To Mid/ lower Pole of Left Kidney; International Journal of Latest research in Science and Technology, Volume 4, Issue 2, March-April 2015,Page no-106-108.

[10] K.Thyagaraju, V. Subhadra Devi: Crossed Fused Renal Ectopia (CRE) In A Fetus With Left Sided PolydactylyA Case Report; International Journal of Basic and Applied Medical Sciences, 2013, Vol 3 (1), JanuaryMarch,pp-161-164.

[11] Palit Sukanya, Datta Asis Kumar, Tapadar Arunabha; A Rare Presentation Of Rudimentary Ectopic Right Kidney Fused To The Lower Pole Of The Left With Multiple Abrrant Renal Vessels- A Case Report, Journal of Anatomical Society of India, 2008, 57 (2), 146-150.

[12] Nussbaum AR, Hartman DS, Whitley N: Multicystic dysplasia and crossed renal ectopia, American Journal of Roentgenology, 1987, 149, 407-410.

[13] Ashley DJ, Mostofi FK; Renal Agenesis and Dysgenesis; J Urol.1960 (Mar); 83:211-30.

[14] Potter EL; Bilateral absence of ureters and kidneys; A report of 50 cases, Obstet. Gynaecol, 1965. Jan; 25;312.

[15] Bhagat Kumar potu, Boopathi Subramaniam, Peh Suat Cheng; Crossed-fused renal ectopia: a case report; Eur j Anat, 2102,16 (1), 79-81.

[16] Bradhaw A, Donnelly LF, Foreman JW; Thrombocytopenia and abdesnt radii syndrome associated with horseshoe kidney; Pediatr Nephrol, 2000, 14, 29-31.

[17] Cook W A, Stephens FD; Fused kidneys; Morphological study and theory of embryonogenesis; Birth Defects; 1977, 13, 327-340.

[18] Parrots TS, Skandalakis JE, Gray SW; The kidney and ureters; In: Embryology for Surgeons, 1994, $2^{\text {nd }}$ edt, pp594-670.
[19] Carleton A; crossd ectopia of kidney and its possible cause; J Anat; 1937, 71, (Pt 2), 292-298.

[20] Suvendu Mahapatra, Jayashree Mohanty : Crossed Fused Renal Ectopia, A Rare Case Presenting With Pain Abdomen; Indian Journal of Medial Case Reports; 2013, Vol-2 (4), October-December,pp-30-33.

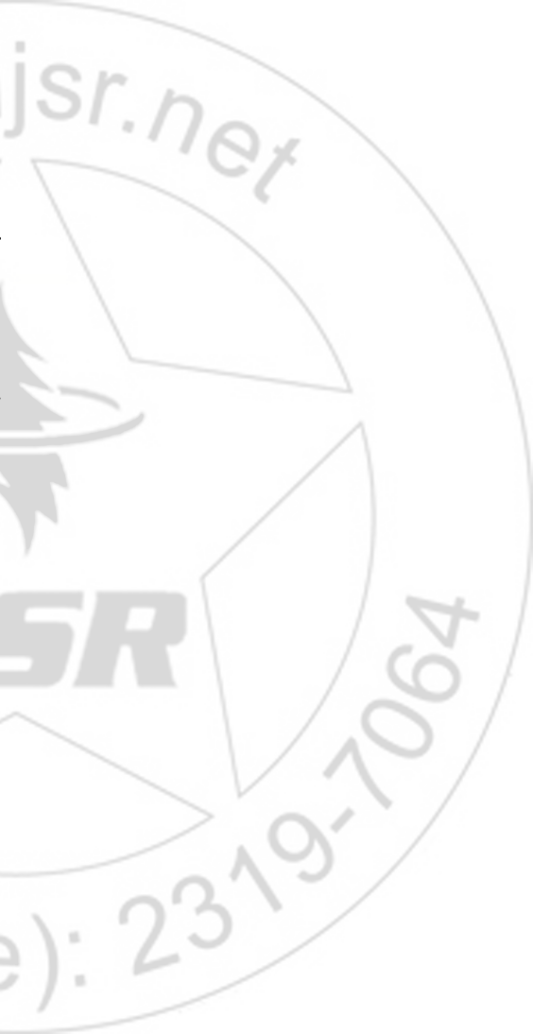

